\title{
Astigmatic Results of a Diffractive Trifocal Toric IOL Following Intraoperative Aberrometry Guidance
}

This article was published in the following Dove Press journal: Clinical Ophthalmology

\author{
John F Blaylock' \\ Brad Hall $\mathbb{D}^{2}$ \\ 'Valley Laser Eye Centre, Abbotsford, \\ BC, Canada; ${ }^{2}$ Sengi, Penniac, NB, Canada
}

Purpose: To determine if intraoperative aberrometry (IA) improves astigmatic outcomes for trifocal toric IOL (TTI) cases.

Patients and Methods: This was a retrospective study examining 137 eyes that underwent cataract extraction and TTI implantation using femtosecond laser, digital registration, and IA. Final cylinder power and axis of placement were determined by IA. Monocular uncorrected distance visual acuity (UDVA), uncorrected intermediate visual acuity (UIVA), uncorrected near visual acuity (UNVA), and refractive data were collected at 3 months. Postoperative residual astigmatism (PRA) determined by manifest refraction was compared to backcalculated residual astigmatism (BRA) using the cylinder power calculated preoperatively. Results: Postoperatively, $97.8 \%$ of eyes had IA PRA $\leq 0.50 \mathrm{D}$ and $80.3 \%$ had BRA $\leq 0.50$ $\mathrm{D}$, a difference of $17.5 \%$. Mean PRA for IA was $0.07 \mathrm{D} \pm 0.19$ (range $0.00-1.00 \mathrm{D}$ ) compared to BRA $0.31 \mathrm{D} \pm 0.33$ (range $0.00-1.34 \mathrm{D})(\mathrm{P}<0.001)$. Cylinder power was changed in $50.4 \%$ of cases based upon IA. Postoperative mean UDVA (LogMAR) was 0.04 \pm 0.09 (range $-0.12-0.30 \operatorname{logMAR}$ ), and $65 \%$ of eyes were $\leq 0.0,85 \% \leq 0.1$, and $99 \% \leq$ 0.18 .

Conclusion: The proportion of eyes with PRA $\leq 0.50 \mathrm{D}$ and mean PRA was significantly lower using IA versus the preoperative planned cylinder power.

Keywords: PanOptix, trifocal IOL, toric IOL, cataract surgery

\section{Plain Language Summary}

Cataract surgery involves removing the opaque natural lens of the eye and replacing it with an artificial intraocular lens. Many cataract surgery patients have astigmatism, which occurs when the front of the eye (cornea) is curved differently in one direction compared to the other (eg the cornea is shaped like a football instead of a soccer ball). Toric intraocular lenses (IOL) are used to correct astigmatism. By measuring several features of the eye, including eye length and the curvature of the cornea, a surgeon can select the best power for the toric IOL. Successful power selection often depends on the accuracy of these measurements. Appropriate power choice is crucial for reducing patient need for glasses to see clearly after surgery. An intraoperative aberrometer (IA) is a device that allows surgeons to perform measurements of the eye during cataract surgery and confirm or refine their power selection. This study was a chart review and was designed to compare results using an IA to theoretical results had the IA not been used. Results show significant benefits to using an IA during surgery to confirm or refine IOL power selection. There was less astigmatism for patients compared to theoretical results had the IA not been used, which provides clearer vision after surgery.
Correspondence: Brad Hall

Sengi, 473 Route 628, Penniac, NB E3A

$8 \times 8$, Canada

Tel + I 888-255-8680

Email bhall@sengiclinical.com 


\section{Introduction}

Cataract surgery remains one of the most common surgical procedures performed worldwide. It is a refractive procedure, and patients increasingly expect to reduce their spectacle dependence following intraocular lens (IOL) implantation. Monofocal IOLs allow patients to reduce their spectacle dependence at distance, however patients may still require spectacles to see clearly at near and intermediate.

Multifocal IOLs were developed to overcome the limitations of using only one focus. Initially, multifocal IOLs were primarily bifocal and provided adequate vision at near and distance, however patients were not always able to see clearly at intermediate. ${ }^{1}$ Trifocal IOLs are designed to split light into 3 foci (distance, intermediate, and near) and to provide good visual acuity at all ranges of vision. The AcrySof ${ }^{\circledR}$ PanOptix ${ }^{\circledR}$ IOL (Alcon Laboratories, Inc., Fort Worth, TX, USA) is currently the only trifocal IOL approved by the US FDA. Studies of this trifocal IOL have reported good visual acuity at all ranges of vision (distance, intermediate, and near), ${ }^{2,3}$ although, as with other multifocal IOLs, mild visual disturbances have also been reported. ${ }^{4,5}$

Postoperative astigmatism can cause suboptimal visual outcomes in patients with multifocal IOLs. Each diopter of postoperative astigmatism may decrease uncorrected distance visual acuity (UDVA) by 1.5 lines. ${ }^{6}$ Surgical approaches to correct astigmatism include corneal incisions, corneal refractive surgery, and toric IOL implantation. ${ }^{7-9}$ However, better visual outcomes with the use of toric IOLs have been reported. ${ }^{10}$

With toric IOL implantation, precise cylinder power selection and axis placement are necessary for optimal refractive outcomes. Intraoperative aberrometry (IA) can be used to measure aphakic and pseudophakic eyes during cataract surgery. Recommendations for spherical and cylindrical IOL power can be obtained by measuring the aphakic state, while examining the pseudophakic state assists the surgeon to determine if adjusting the orientation of the implanted IOL could improve refractive outcomes. ${ }^{11}$ The ORA System (Alcon Laboratories, Inc., Fort Worth, TX, USA), is commonly used and is reported to provide improved refractive outcomes compared to conventional preoperative planning. ${ }^{12}$

Studies have reported on refractive outcomes of the AcrySof $^{\circledR}$ PanOptix ${ }^{\circledR}$ toric IOL. ${ }^{13,14}$ However, to our knowledge, there are few studies that have compared outcomes after trifocal toric implantation with and without IA. The purpose of this study is to determine if IA improves astigmatic outcomes for trifocal toric IOL cases and to compare to conventional preoperative planning.

\section{Patients and Methods}

This was a retrospective chart review of astigmatic outcomes at a single site (Valley Laser Eye Centre, Abbotsford, BC, Canada) of a diffractive trifocal toric IOL with FLACS, DT, and IA utilized during implantation. Patient chart data were de-identified. This study was conducted in compliance with Good Clinical Practice (GCP), International Harmonization (ICH) guidelines, and the tenets of the Declaration of Helsinki. An institutional review board (Advarra IRB, Columbia, MD) approved the study (Pro00035969). Patient informed consent was obtained for the use of chart data.

Subjects were included if they presented with visually significant cataracts or as a candidate for clear lens extraction (clear lens extraction is off-label), showed interest in and were eligible for implantation of a diffractive toric IOL. Exclusion criteria were ocular comorbidity that may affect post-operative visual acuity, or irregular corneal astigmatism and keratoconus.

Data records were used to identify subjects that fit the inclusion and exclusion criteria above. The chart review identified 137 eyes that fit the inclusion and exclusion criteria above, and all 137 eyes were included in the study. De-identified data included data from the preoperative and postoperative examinations. Preoperative and postoperative data included sex, age, refractive error, and visual acuity (UDVA, UIVA, UNVA, BCVA). Visual acuities were recorded in Snellen and converted to the equivalent $\log$ of the minimum angle of resolution (logMAR) notation for statistical analysis.

A LenSx femtosecond laser (Alcon Laboratories, Inc., Fort Worth, TX, USA) was used for corneal incisions, capsulotomy, and lens fragmentation. Patients received preoperative biometry measurements using the IOL Master 500 (Carl Zeiss Meditec, Jena, Germany). Topography was performed with the Atlas 9000 (Carl Zeiss Meditec, Jena, Germany) and tomography was performed using the Pentacam (Oculus, Wetzlar, Germany). To determine IOL power preoperatively, biometry data was entered into the Barrett Universal II online calculator ${ }^{15}$ and the AlconBarrett Toric online calculator. ${ }^{16}$ The VERION System was used for image-guided digital tracking. The ORA System with Verifeye+ (Alcon Laboratories, Inc., Fort 
Worth, TX, USA) was used intraoperatively to determine spherical power, cylinder power, and axis of placement. The surgeon's usual standard of care for patients implanted with advanced technology IOLs was the postoperative regimen.

Acrysof IQ Panoptix toric IOL models were implanted (TFNT20, TFNT30, TFNT40, TFNT50, TFNT60; Alcon Laboratories, Inc., Fort Worth, TX, USA). Acrysof Panoptix IQ IOLs are designed as diffractive aspheric opticals. ${ }^{17}$ They are based on quadrifocal design, with focal points at near $(40 \mathrm{~cm})$, intermediate $(60 \mathrm{~cm})$, and distance $(\infty)$, but functionally is a trifocal IOL. ${ }^{18}$

The primary outcome measure of interest was the manifest refraction and specifically the percentage of eyes that were $\leq 0.5 \mathrm{D}$ in their postoperative residual astigmatism (PRA) at the 3 months postoperative visit. Secondary endpoints included manifest refraction spherical equivalent (MRSE), and monocular uncorrected visual acuities at distance (UDVA; 6m), intermediate (UIVA; 60cm), and near (UNVA; 40cm) and best-corrected visual acuity (BCVA).

The preoperative planned cylinder power was not always the same power as that suggested by IA. Where there were differences, the cylinder power suggested by IA was chosen. Back-calculations were performed to simulate the refractive error had the preoperative planned cylinder power and axis of placement been used. First described by Hill et al, ${ }^{19}$ backcalculations can simulate removal of the implanted IOL and replacement with the preoperative planned cylinder power and axis of placement. Residual astigmatism after IOL implantation is a combination of 4 vectors: preoperative corneal astigmatism, surgically induced astigmatism, random surgical effects, and the IOL. By mathematically replacing the IOL vector with another, back-calculations can determine the refractive error had the preoperative planned cylinder power and axis of placement been used. Backcalculations were performed by crossed vector analysis of two vectors. The primary vector was the absolute difference in power at the corneal plane between the implanted and suggested IOLs, and the preoperative steep axis, while the secondary vector was the postoperative cylinder power and axis. The primary and secondary vectors were calculated for each eye, input into the Eye Vectors iPhone Application Version 2.0 (Cambui Labs), and the resulting crossed vector result was recorded. Vector analysis was conducted after descriptive and other analytical statistics.

Statistical analyses were performed using the software program R (version 3.6.3; The R Foundation for Statistical Computing, Vienna, Austria). Differences in continuous variables were compared using a paired $t$-test for two continuous variables or an analysis of variance (ANOVA) for 3 or more groups. In all cases, $\mathrm{p} \leq 0.05$ was considered significant.

\section{Results}

The chart review identified 137 eyes of 86 patients for inclusion in this study. Our study included approximately equal numbers of males (44) and females (42), who had an average age of $64.1 \pm 7.8$ (range 47-86). The demographic and preoperative data are summarized in Table 1. All patients were scheduled for FLACS, however two eyes were not able to receive FLACS due to insufficient pupil dilation, and were converted to conventional phacoemulsification.

A comparison of the distributions of postoperative absolute prediction error for IA and back-calculated absolute prediction error is shown in Figure 1. For IA, 83.9\% (115/137) and 95.6\% (131/137) of eyes had an absolute prediction error of $0.25 \mathrm{D}$ and $0.5 \mathrm{D}$, respectively. Compared to IA, the percentage of patients with an absolute prediction error of $0.25 \mathrm{D}$ and $0.5 \mathrm{D}$ was lower for back-calculations using preoperative planned power: $72.3 \% \quad(99 / 137)$ and $90.5 \%$ (124/137) respectively. Additionally, using the preoperative planned power could have resulted in 1 eye having MRSE greater than $1 \mathrm{D}$.

Figure 2 shows the distribution of the PRA for IA compared to back-calculated residual astigmatism (BRA). It demonstrates that a higher percentage of IA eyes, 90.5\% (124/137) and 97.8\% (134/137), had PRA of $0.25 \mathrm{D}$ and $0.50 \mathrm{D}$, respectively, than back-calculations using preoperative planned power. For the back-calculations, 45.0\% (61/ $137)$ and $80.0 \%(109 / 137)$ had BCA $0.25 \mathrm{D}$ and $0.50 \mathrm{D}$, respectively. Additionally, no IA eyes had postoperative astigmatism greater than $1.0 \mathrm{D}$, compared to $6.0 \%(8 / 137)$ in back-calculations using preoperative planned cylinder power.

Table I Preoperative Patient Demographics

\begin{tabular}{|l|l|}
\hline Parameters & Mean \pm SD (Range) \\
\hline Number of eyes (patients) & $137(86)$ \\
Post-Operative Visit (days) & $70.1 \pm 29.3(43-222)$ \\
Age (yr) & $64.1 \pm 7.8(47-86)$ \\
\hline Sex & \\
$\quad$ Male (n) & 44 \\
Female (n) & 42 \\
\hline Axial Length (mm) & $24.23 \pm 1.23(21.74-28.29)$ \\
Cylinder (D) & $1.01 \pm 0.50(0.18-2.77)$ \\
\hline
\end{tabular}




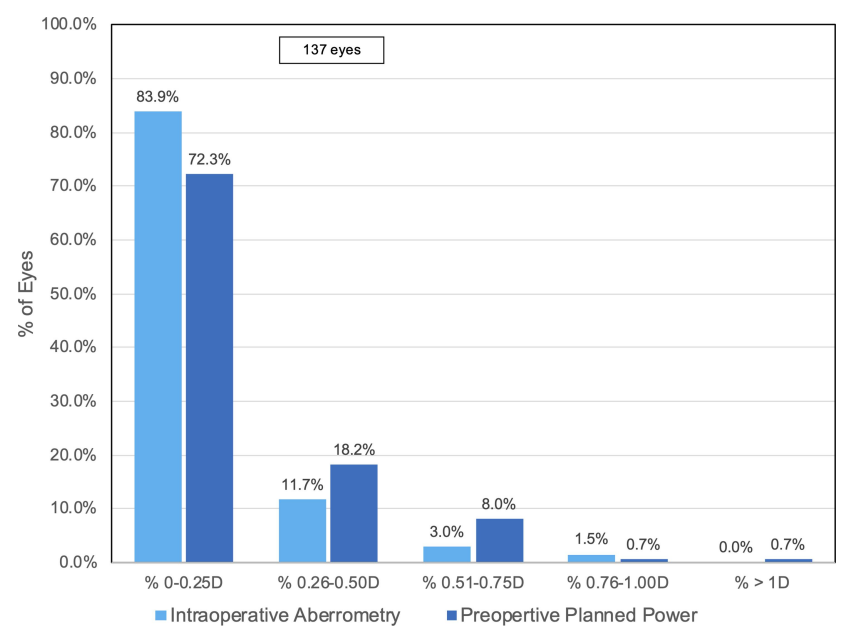

Figure I Postoperative refractive prediction errors in eyes using intraoperative aberrometry and preoperative calculations.

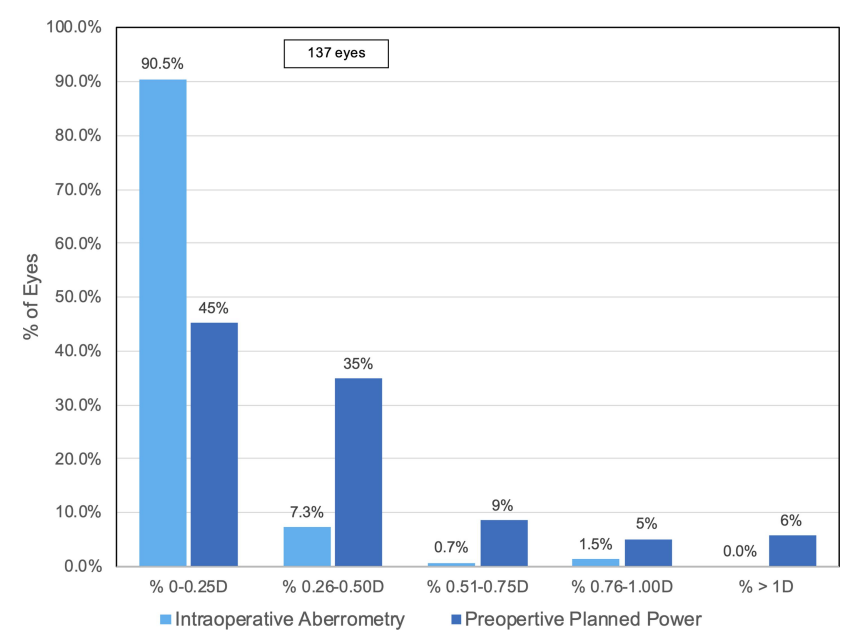

Figure 2 Postoperative residual astigmatism in eyes using intraoperative aberrometry and preoperative calculations.

The postoperative monocular visual acuities are summarized in Table 2. Patients had good visual acuity at all ranges of vision-distance, intermediate, and near. Monocular UDVA, BCVA, UIVA, and UNVA were 0.10 $\log$ MAR or better in $84.7 \%(116 / 137), 98.5 \%$ (135/137), $99.3 \% \quad(136 / 137)$, and $73.0 \% \quad(100 / 137)$ of eyes, respectively. Almost all eyes had UDVA, BCVA, UIVA, and UNVA of $0.18 \operatorname{logMAR}$ or better. Mean UDVA was $0.04 \pm 0.09 \log$ MAR (range $-0.12-0.30 \log$ MAR).

A comparison of refractive outcomes between implanted eyes with the power suggested by IA to backcalculated refractive outcomes is shown in Table 3. The preoperative planned power and IA suggested different cylinder power in $50.4 \%(69 / 137)$ of cases. The PRA was significantly lower with IA $(0.07 \pm 0.19 \mathrm{D}$; range $0.00-1.00 \mathrm{D})$ compared to BRA $(0.31 \pm 0.33 \mathrm{D}$; range $0.00-1.34 \mathrm{D}$; paired $t$-test, $\mathrm{P}<0.001)$. Postoperative MRSE was also significantly lower with IA $(0.01 \pm 0.27$ $\mathrm{D}$; range $-0.88-1.00 \mathrm{D})$ compared to back-calculated MRSE $(0.13 \pm 0.27 \mathrm{D}$; range $-0.71-1.17 \mathrm{D}$; paired $t$-test, $\mathrm{P}<0.001)$. Mean absolute prediction error was significantly lower with IA, at $0.19 \pm 0.19 \mathrm{D}$ (range $0.00-0.96$ $\mathrm{D})$, compared to preoperative planned power $(0.23 \pm 0.23$ $\mathrm{D}$; range $0-1.09 \mathrm{D})$; paired $t$-test, $(\mathrm{p}=0.038)$.

Figure 3 shows double-angle vector plots for preoperative astigmatism, PRA, and BRA. The standard deviation for PRA and BRA, $0.2 \mathrm{D}$ and $0.45 \mathrm{D}$, respectively, were lower compared to the preoperative astigmatism $(1.08 \mathrm{D})$. The standard deviation for PRA was also lower than that of the BRA.

\section{Discussion}

We found that astigmatic outcomes were improved with IA for trifocal toric IOL cases and were better than the results of back-calculations using preoperative planned cylinder power. The primary outcome measure for this study was the percentage of eyes that were $\leq 0.5 \mathrm{D}$ in their PRA. Our results appear as good or lower compared to previous reports of TTI with the Acrysof Panoptix IQ IOL..$^{13,14,20,21}$ Carreño et $\mathrm{al}^{13}$ reported that approximately $66 \%$ and $94 \%$ of patients were $\leq 0.25 \mathrm{D}$ and $\leq 0.5 \mathrm{D}$ in their PRA, compared to $90.5 \%$ and $97.8 \%$ in our study. In both studies, the VERION and ORA systems were used. A possible explanation for the difference in percentage of eyes that were $\leq 0.25 \mathrm{D}$ is that the authors reported using FLACS in 53\% of eyes, while our

Table 2 Postoperative Monocular Visual Acuity

\begin{tabular}{|l|l|l|l|l|l|l|l|}
\hline Acuity & $\begin{array}{l}\text { Mean } \pm \text { SD (Range) } \\
\text { logMAR }\end{array}$ & $\begin{array}{l}\% \mathbf{0 . 4 0} \\
\text { logMAR or } \\
\text { Better }\end{array}$ & $\begin{array}{l}\% \mathbf{0 . 3 0} \\
\text { logMAR or } \\
\text { Better }\end{array}$ & $\begin{array}{l}\text { \% } \mathbf{0 . 1 8} \\
\text { logMAR or } \\
\text { Better }\end{array}$ & $\begin{array}{l}\% \mathbf{0 . 1 0} \\
\text { logMAR or } \\
\text { Better }\end{array}$ & $\begin{array}{l}\text { \% } \mathbf{0 . 0 0} \\
\text { logMAR or } \\
\text { Better }\end{array}$ & $\begin{array}{l}\%-\mathbf{0 . 1 2} \\
\text { logMAR or } \\
\text { Better }\end{array}$ \\
\hline UDVA & $0.04 \pm 0.09(-0.12-0.30)$ & 100 & 100 & 98.5 & 84.7 & 64.7 & 10.2 \\
BCVA & $0.00 \pm 0.06(-0.12-0.18)$ & 100 & 100 & 100 & 98.5 & 87.6 & 10.9 \\
UIVA & $-0.07 \pm 0.08(-0.12-0.40)$ & 100 & 99.3 & 99.3 & 99.3 & 94.9 & 64.2 \\
UNVA & $0.04 \pm 0.07(0.00-0.30)$ & 100 & 100 & 98.5 & 90.5 & 73.0 & 0 \\
\hline
\end{tabular}


Table 3 Postoperative Refractive Outcomes

\begin{tabular}{|l|l|l|l|}
\hline Parameters & IA Mean \pm SD (Range) & PreOP Planned Power Mean \pm SD (Range) & P value* \\
\hline Residual Astigmatism (D) & $0.07 \pm 0.19(0.00-1.00)$ & $0.31 \pm 0.33(0.00-1.34)$ & $<0.001$ \\
MRSE (D) & $0.01 \pm 0.27(-0.88-1.00)$ & $0.13 \pm 0.27(-0.71-1.17)$ & $<0.001$ \\
Prediction Error & $0.19 \pm 0.19(0.00-0.96)$ & $0.23 \pm 0.23(0.00-1.09)$ & 0.038 \\
\hline
\end{tabular}

Note: *Paired t-test.

Abbreviations: IA, intraoperative aberrometry; PreOP, preoperative; MRSE, manifest refraction spherical equivalent.

study used FLACS in $98.5 \%$ percent of eyes. However, Carreño et $\mathrm{al}^{13}$ reported no significant differences between FLACS and standard surgery in their results. Other causes for the differences observed in our study could be the length of follow-up and preoperative refraction. It is interesting to note that the results reported by Carreño et $\mathrm{al}^{13}$ for percentage of eyes $\leq 0.25 \mathrm{D}(66 \%)$ appear in between our results of BRA and PRA (45\% and $90.5 \%$, respectively).

Mean postoperative cylinder after TTI with the Acrysof Panoptix IQ IOL has been reported previously between -0.21 and $0.28 .^{13,14,20,21}$ Our results with IA $0.07 \pm 0.19$ $\mathrm{D}$ fall close to the middle of this range, while the results of our back-calculations using preoperative planned power, $0.31 \pm 0.33 \mathrm{D}$ fall outside it. Postoperative MRSE in our study $(0.01 \pm 0.27 \mathrm{D})$ fell close to the middle of the range for previously published results $(-0.07-0.12 \mathrm{D})^{14,20,21}$ of TTI with the Acrysof Panoptix IQ IOL.

Visual acuities in this study were similar to previous reports of implantation of the Acrysof Panoptix IQ toric IOL. ${ }^{14,20,21}$ Kohnen et $\mathrm{al}^{20}$ reported similar results of monocular UDVA, UIVA, and UNVA of $0.02,0.12$, and $0.10 \log$ MAR respectively with the Acrysof Panoptix IQ toric IOL, compared UDVA, UIVA, and UNVA of 0.04 , -0.07 , and $0.04 \log$ MAR reported in this study, though the sample size was smaller in their study.
We found that our method of back-calculation provided a useful technique to compare refractive outcomes of implantations using the preoperative planned power and the power suggested by IA. A significant benefit of back-calculations is that they eliminate the need for multiple groups of patients (such as those that receive the preoperative planned power and those that receive the IA suggested power) because each patient eye provides data for each group. One drawback of our method of back-calculation is the need to manually input each vector for each crossed vector analysis into the application, which can be time consuming.

Our postoperative results and back-calculations show that using IA improved refractive outcomes compared to preoperative planning. The prediction error was significantly higher with preoperative planning, as were the residual astigmatism and postoperative MRSE.

A limitation of this study is that it was a retrospective study and not a prospective study. Additionally, the measured outcomes included refractive error and visual acuity, but other measures such as patient satisfaction could have been useful to report.

\section{Conclusions}

In summary, IA demonstrated improved accuracy of astigmatic outcomes in cases of trifocal toric implantation.
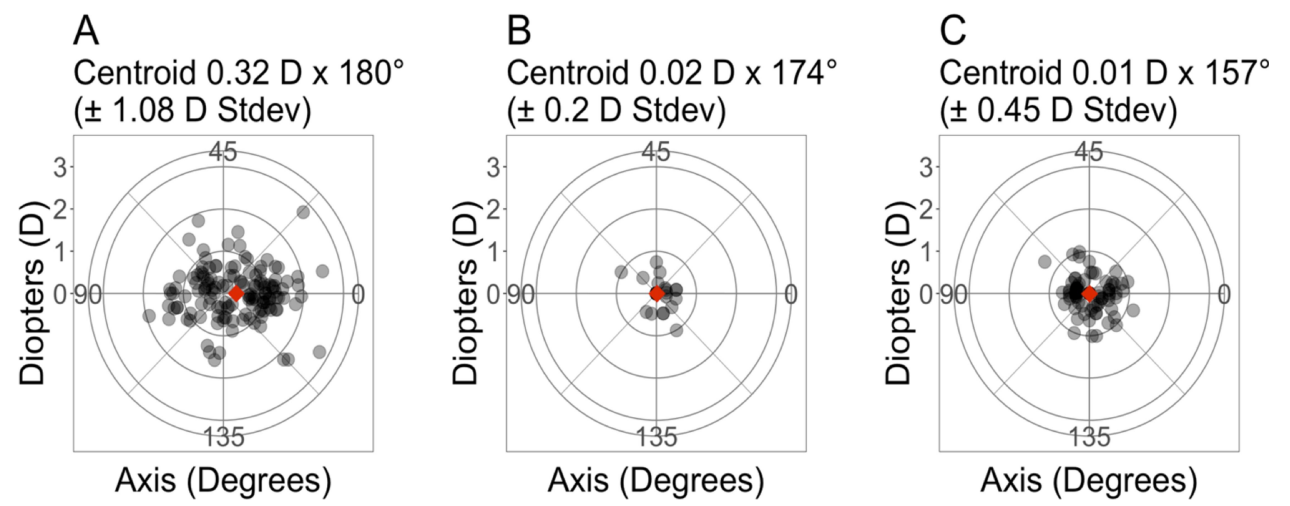

Figure 3 Double-angle vector plots of astigmatism vectors for (A) Preoperative, (B) Intraoperative Aberrometry, and (C) Preoperative Planned Power. Each ring represents I D. The diamond represents the centroid. $\mathrm{N}=137$ eyes. 
Postoperatively, patients had excellent refractive outcomes and visual performance at all ranges.

\section{Acknowledgments}

This paper was presented at the 2020 ASCRS Virtual Annual Meeting with interim findings. The paper's abstract was published online and is available at: https:// ascrs.org/clinical-education/presbyopia/2020-pod-sps-10868216-astigmatic-results-of-a-diffractive-trifocal-iol-

following-intraope. This study was supported with an investigator-initiated study grant (51461169) from Alcon, Fort Worth, TX, USA.

\section{Disclosure}

J. F. Blaylock is a consultant to Alcon Laboratories, Inc. and is affiliated with Valley Laser Eye Centre. Brad Hall is affiliated with Sengi and reports personal fees from Valley Laser Eye Centre, during the conduct of the study. The authors report no other conflicts of interest in this work.

\section{References}

1. Gatinel D, Houbrechts Y. Comparison of bifocal and trifocal diffractive and refractive intraocular lenses using an optical bench. $J$ Cataract Refract Surg. 2013;39:1093-1099. doi:10.1016/j. jcrs.2013.01.048

2. Alfonso JF, Fernandez-Vega-Cueto L, Fernandez-Vega L, MontesMico R. Visual function after implantation of a presbyopia-correcting trifocal intraocular lens. Ophthalmic Res. 2019:1-13.

3. Alio JL, Plaza-Puche AB, Alio Del Barrio JL, et al. Clinical outcomes with a diffractive trifocal intraocular lens. Eur $J$ Ophthalmol. 2018;28:419-424. doi:10.1177/1120672118762231

4. Cochener B, Lafuma A, Khoshnood B, Courouve L, Berdeaux G. Comparison of outcomes with multifocal intraocular lenses: a meta-analysis. Clin Ophthalmol. 2011;5:45-56.

5. de Silva SR, Evans JR, Kirthi V, Ziaei M, Leyland M. Multifocal versus monofocal intraocular lenses after cataract extraction. Cochrane Database Syst Rev. 2016;12:CD003169.

6. Lehmann RP, Houtman DM. Visual performance in cataract patients with low levels of postoperative astigmatism: full correction versus spherical equivalent correction. Clin Ophthalmol. 2012;6:333-338.

7. Budak K, Friedman NJ, Koch DD. Limbal relaxing incisions with cataract surgery. $J$ Cataract Refract Surg. 1998;24:503-508. doi:10.1016/S0886-3350(98)80292-7
8. Norouzi H, Rahmati-Kamel M. Laser in situ keratomileusis for correction of induced astigmatism from cataract surgery. J Refract Surg. 2003;19:416-424.

9. Mozayan E, Lee JK. Update on astigmatism management. Curr Opin Ophthalmol. 2014;25:286-290. doi:10.1097/ICU.0000000000000068

10. Kessel L, Andresen J, Tendal B, Erngaard D, Flesner P, Hjortdal J. Toric intraocular lenses in the correction of astigmatism during cataract surgery: a systematic review and meta-analysis. Ophthalmology. 2016;123:275-286. doi:10.1016/j.ophtha.2015.10.002

11. Hatch KM, Woodcock EC, Talamo JH. Intraocular lens power selection and positioning with and without intraoperative aberrometry. $J$ Refract Surg. 2015;31:237-242. doi:10.3928/1081597X-201503 19-03

12. Ianchulev T, Hoffer $\mathrm{KJ}$, Yoo $\mathrm{SH}$, et al. Intraoperative refractive biometry for predicting intraocular lens power calculation after prior myopic refractive surgery. Ophthalmology. 2014;121:56-60. doi:10.1016/j.ophtha.2013.08.041

13. Carreno E, Carreno EA, Carreno R, Carreno M, Lopez V, Potvin R. Refractive and visual outcomes after bilateral implantation of a trifocal intraocular lens in a large population. Clin Ophthalmol. 2020;14:369-376. doi:10.2147/OPTH.S238841

14. Rementeria-Capelo LA, Contreras I, Garcia-Perez JL, Blazquez V, Ruiz-Alcocer J. Visual quality and patient satisfaction with a trifocal intraocular lens and its new toric version. J Cataract Refract Surg. 2019;45:1584-1590. doi:10.1016/j.jcrs.2019.06.014

15. Barrett GD Barrett Universal II Formula. Singapore, Asia-Pacific Association of Cataract and Refractive Surgeons. Available from: https://calc.apacrs.org/barrett_universal2105/. Accessed May 31, 2018.

16. Barrett GD Alcon-Barrett Online Toric Calculator. Alcon. Available from: https://www.myalcon-toriccalc.com/\#/calculator. Accessed May 18, 2020.

17. Ruiz-Mesa R, Abengozar-Vela A, Ruiz-Santos M. A comparative study of the visual outcomes between a new trifocal and an extended depth of focus intraocular lens. Eur J Ophthalmol. 2018;28:182-187. doi: $10.5301 /$ ejo. 5001029

18. Kohnen T. First implantation of a diffractive quadrafocal (trifocal) intraocular lens. J Cataract Refract Surg. 2015;41:2330-2332. doi:10.1016/j.jcrs.2015.11.012

19. Hill W, Osher R, Cooke D, et al. Simulation of toric intraocular lens results: manual keratometry versus dual-zone automated keratometry from an integrated biometer. $J$ Cataract Refract Surg. 2011;37:2181-2187. doi:10.1016/j.jcrs.2011.06.028

20. Kohnen T, Lwowski C, Hinzelmann L, et al. Presbyopia correction in astigmatic eyes using a toric trifocal intraocular lens with quadrifocal technology. J Refract Surg. 2020;36:638-644. doi:10.3928/ 1081597X-20200729-04

21. Ribeiro FJ, Ferreira TB. Comparison of visual and refractive outcomes of 2 trifocal intraocular lenses. J Cataract Refract Surg. 2020;46:694-699. doi:10.1097/j.jcrs.0000000000000118
Clinical Ophthalmology

\section{Publish your work in this journal}

Clinical Ophthalmology is an international, peer-reviewed journal covering all subspecialties within ophthalmology. Key topics include: Optometry; Visual science; Pharmacology and drug therapy in eye diseases; Basic Sciences; Primary and Secondary eye care; Patient Safety and Quality of Care Improvements. This journal is indexed on PubMed
Central and CAS, and is the official journal of The Society of Clinical Ophthalmology (SCO). The manuscript management system is completely online and includes a very quick and fair peer-review system, which is all easy to use. Visit http://www.dovepress.com/ testimonials.php to read real quotes from published authors.

\section{Dovepress}

